\title{
Apolipoprotein L1 associated nephropathy; an overview
}

\author{
Mohsen Akhavan Sepahi ${ }^{1}$, LVKS Bhaskar ${ }^{2,3}{ }^{\circledR}$, Audrey Tolouian $^{4}{ }^{\complement}, \operatorname{Ramin}_{\text {Tolouian }^{5 *}}{ }^{5}$ \\ ${ }^{1}$ Department of Pediatric Nephrology, School of Medicine and Pediatric Clinical Research of Development Center, Qom University of \\ Medical Sciences, Qom, Iran \\ ${ }^{2}$ Sickle Cell Institute Chhattisgarh, Raipur (CG), India \\ ${ }^{3}$ Department of Zoology, Guru Ghasidas University, Bilaspur, 495009 (CG), India \\ ${ }^{4}$ The University of Texas at El Paso, School of Nursing, El Paso, TX, USA \\ ${ }^{5}$ Division of Nephrology, College of Medicine, University of Arizona, Tucson, AZ, USA
}

\section{A R T I CLE I N F O}

\section{Article Type:}

Review

\section{Article History:}

Received: 27 September 2019

Accepted: 27 October 2019

Published online: 15 November 2019

\section{Keywords:}

Apolipoprotein L1, Chronic kidney disease, End-stage renal disease, Focal segmental glomerulosclerosis, HIVassociated nephropathy, APOL1-related nephropathy, Podocye

\begin{abstract}
A B S T R A C T
Genetic variants of apolipoprotein L1 (APOL1) have been recognized as a risk factor for kidney disease in people of African ancestry. APOL1 mediate renal damage in podocytes through necrosis, apoptosis and pyroptosis processes. APOL1 gene contains G1 and G2 alleles that mediate in increasing risk of renal disorders in African Americans. People who carry APOL1 risk alleles have a three to four-fold increase risk for non-diabetic renal disease (NDRD), Idiopathic focal segmental glomerulosclerosis (FSGS) and HIV-associated nephropathy (HIVAN). Therefore, identifying genetic factors involved in the pathogenesis of renal disorders, including APOL1 risk variants, may help to improve our understanding of kidney problems.
\end{abstract}

Implication for health policy/practice/research/medical education:

Apolipoprotein L1 risk variants are more common in some races. Apolipoprotein L1 risk variants are involved in various CKDs. The APOL1 involves necrosis, apoptosis and pyroptosis processes in various types of kidney cells including podocytes.

Please cite this paper as: Akhavan Sepahi M, Bhaskar LVKS, Tolouian A, Tolouian R. Apolipoprotein L1 associated nephropathy; an overview. J Renal Inj Prev. 2019; 8(4): 311-315. DOI: 10.15171/jrip.2019.57.

\section{Introduction}

Chronic kidney disease $(\mathrm{CKD})$ is one of the major public health problems, including renal replacement therapy. Advanced CKD is associated with adverse outcomes and disability $(1,2)$. CKD is categorized based on its etiology, kidney function (GFR category), and markers of kidney damage (albuminuria category) (3). Several studies identified some genetic factors that contribute to the progression of CKD in non-diabetic African-American race (4). The prevalence of end-stage renal disease (ESRD) is five times greater in people with African ancestors than the Caucasians. This led to the identification of some genetic factors that are contributing to renal disease in these populations. Apolipoprotein L1 (APOL1) protein that encoded by the human APOL1 gene is one of the risk factors for non-diabetic renal disease (NDRD) in the African ancestors' population (5). Secretory lipoprotein,
APOL1 circulates in HDL3 complexes and is expressed in various tissues (6). Genetic studies show that the two G1 and G2 alleles of the APOL1 gene are significantly associated with the risk of various types kidney diseases including NDRD, Idiopathic focal segmental glomerulosclerosis (FSGS) and HIV-associated nephropathy (HIVAN) in African Americans (7). The APOL1 and MYH9 were identified as independent nephropathy susceptibility loci in African-American with FSGS and other CKDs (8-10). This review discusses the current knowledge regarding pathophysiological and clinical aspects of APOL1, including its role in renal disease.

\section{Materials and Methods}

Articles related to this topic were searched in Web of Science, PubMed, Embase, Scopus and the directory of open access journals (DOAJ), using specific combination 
of keywords. The keywords used are apolipoprotein L1, nephropathy, CKD, ESRD and APOL1-related nephropathy.

\section{APOL1 genetic variants}

The human APOL family of proteins is mainly involved in lipid transport and metabolism. APOL1 risk alleles exhibit increased risk for hyperlipidemia, obesity and atherosclerosis (11). In addition, APOL family is involved in innate host immunity, apoptosis and autophagy due to their structural similarities with bacterial colicins and other Bcl-2 family of proteins (12). The human APOL family consists of six genes that are located on chromosome 22q12.3. APOL1 is produced by hepatocytes and is part of the circulating HDL complex. It expressed in various cell types including macrophages, kidney, brain and pancreas $(4,13,14)$. APOL1 gene is associated with some diseases, including schizophrenia, prostate cancer, liver cancer, and breast cancer (15). The last exon of the APOL1 gene harbors two alleles (G1 and G2). G1 includes two mutations (rs73885319 and rs60910145) that result in amino acid substitutions at positions 342 (serine 342 glycine) and 384 (isoleucine 384 methionine). G2 allele (rs71785313) is a 6-base pair in-frame deletion that removes asparagine 388 and tyrosine 389 amino acids (16). G1 and G2 alleles are located 12 base pair apart and are in perfect negative linkage disequilibrium (17). In some populations, G1 allele occurs more frequently (20\%-22\%) than the G2 allele (13\%-15\%). About 10\%$15 \%$ African-Americans have two APOL1 risk alleles (16). The frequency of G1 and G2 varies across Africa. The G1 is more prevalent in west Africa, while the G2 allele is consistently distributed through Africa. Based on the presence of G1 and G2 alleles in Africa, various genotype combinations of risk alleles such as homozygous (G1G1 or G2G2), heterozygous ( $\mathrm{G} 1 \mathrm{G} 0$ or G2G0) and compound heterozygous (G1G2) are possible (Figure 1).

The role of APOL1 genetic variants in kidney disease The FSGS and type 2 diabetes-related CKDs are the prevalent renal disorders in African Americans. Over the past decade, APOL1 mutations have been identified in African individuals and attributed as one of the important risk factors for CKD in this population $(8,13,17)$. The APOL1-associated nephropathy comprises NDRD that include lupus nephritis, hypertensive nephrosclerosis, primary FSGS and HIVAN (18). African Americans carrying APOL1 genotypeshavehigher rates of albuminuria and decreased renal function with faster progression to ESRD than Caucasians $(19,20)$. Immunohistological studies revealed the presence of APOL1 in arteriolar endothelium and epithelium of proximal tubule in normal kidneys, FSGS and HIVAN (21). Surprisingly, APOL1 was detected in the media of medium size arteries and arterioles of both FSGS and HIVAN kidneys but not in

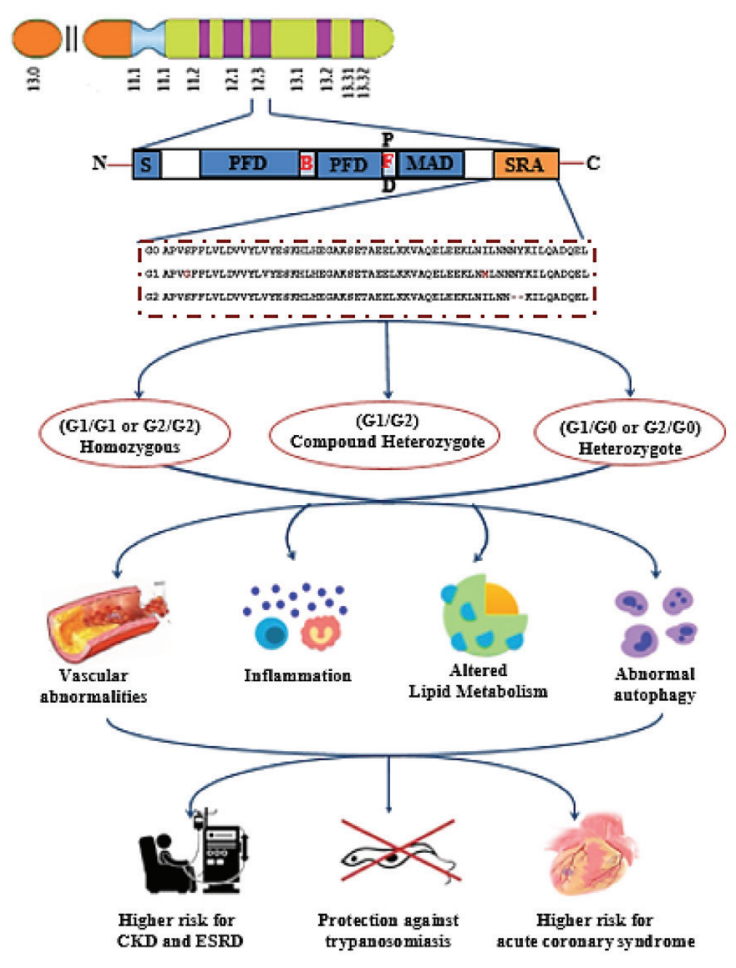

Figure 1. The APOL1 gene risk alleles. The figure depicts the genomic organization of the APOL1 gene on chromosome 22q12.3. Risk alleles are involved in modulation of inflammation by autophagy and altered lipid metabolism. The risk alleles offer protection against trypanosomiasis. Increase risk of cardiovascular disease and renal failure. Note; This illustration is based on the information obtained from existing literature.

normal kidneys (21). Evaluation of associations of APOL1 genotype and urine biomarkers of glomerular and tubular injury in HIV-infected African women demonstrated that the renal damage associated with APOL1 is more likely to be associated with glomerular injury (22). Therefore, the identification of renal APOL1 localization may help elucidate the mechanisms involved in the development of nephropathy. Various histopathologic findings have been documented in relation to APOL1-associated nephropathy in human and animal models, including solidified glomerulosclerosis, sickle cell nephropathy, severe lupus nephritis and FSGS (23). Analysis of renal biopsies of hypertension-attributed CKD in African Americans without nephrotic syndrome showed the presence of obsolescent glomerulosclerosis along with APOL1 risk alleles (24). Furthermore, APOL1 gene alleles were also found in African Americans receiving kidney transplant and these APOL1 alleles were not related to the increased risk of post-transplant allograft dysfunction (25).

In CKD, kidney lesions caused by an array of etiological factors lead to the loss of renal parenchyma and impaired kidney function. Most studies have shown that individuals carrying homozygous (G1G1 or G2G2), heterozygous (G1G0 or G2G0) and compound heterozygous (G1G2) 
forms of APOL1 alleles are susceptible to CKD. Meanwhile, individuals with G1G1 homozygotes showed higher risk for CKD and albuminuria (26). African American patients with CKD who are carriers of two APOL1 risk alleles exhibit faster progression to ESRD compared to the ones who are carriers of zero or one APOL1 risk allele (27).

Despite a strong association between the presence of APOL1 riskvariants and the risk of developing nephropathy, its association with diabetic glomerulosclerosis is unlikely $(9,10,18)$. The APOL1 gene is restricted to humans and several primates. The pathogenic mechanisms of APOL1 risk variants in renal lesions are unclear (24). However, different mechanisms have been considered in relation to APOL1 renal risk variants on renal cells including podocytes and their role in the development of glomerulopathies in vivo.

Mechanisms of cell damage in APOL1-related nephropathy Cellular expression of APOL1 renal risk variants (RRVs) is linked with cell death related processes (apoptosis, necrosis, pyroptosis and autophagy) in various types of cells containing podocytes. This APOL1-mediated cell toxicity leads to swelling of lysosomes, potassium depletion and mitochondrial dysfunction, autophagy, protein kinase receptor activation, ubiquitin D activation, and endoplasmic reticulum stress. However, these effects were found only in cells containing APOL1 RRVs (28). Experimental evidence suggests that the non-risk allele of the APOL1 gene (G0) was shown to provoke autophagic cell death in human colorectal cancer cell lines (29). Whereas the APOL1 G1 and G2 alleles significantly increased the toxicity in HEK-293 cells and podocytes compared to G0 allele (30). However, it still remains unclear whether the increased toxicity occurs through the same or separate mechanism (31).

The major mechanisms that contribute to APOL1 toxicity include lysosome stimulation, apoptosis, autophagy and/ or endocytosis. Recent evidence shows that APOL1 risk alleles interact with genetic or environmental parameters that induce apoptosis in renal cells. The APOL family holds a Bcl-2 homology domain3 within the pore-forming domain; and may act as apoptotic activators and cause autophagic cell death in specific situations (32). APOL1 G1 also induced cytotoxicity either by K-current or activation of the stress-activated protein kinases (SAPK) pathway. The activated SAPKs cause toxicity and cell death through downstream effectors that control the flow of $\mathrm{Na}, \mathrm{Cl}$, and $\mathrm{H} 2 \mathrm{O}$ which leads to cytoplasmic swelling (33). APOL1 proteins are involved in the formation of selective pores of cation $\mathrm{K}$ in the plasma membrane leading to an increase in intracellular K efflux. The efflux of intracellular cation $\mathrm{K}$ subsequently activates p38, c-JUN N-terminal kinase, extracellular signal-regulated kinase and mitogenactivated protein kinase pathways (34).

Experimental data demonstrated that cytokines greatly increase the expression of APOL1 nonrisk (NR) in a variety of cells in vitro. The APOL1 also secreted proteins that are found in circulation and reach lysosomal compartments via endosomal trafficking pathway (35). Silencing of APOL1 enhanced miR193a expression which leads to dedifferentiation of differentiated podocytes. The APOL1 function is dependent on the intact interaction of APOL1-miR193a axis (36). The miR193a negatively regulates Wilms' tumor 1 (WT1), a major transcriptome of podocyte markers like nephrin and podocalyxin. In addition, APOL1 induced podocin, podocalyxin and WT1 in human embryonic kidney cells $(21,28,37)$. Lentivirusmediated of APOL1 variants transduction to human podocyte indicated that the APOL1 risk variants have the potential to induce podocyte injury through enhanced lysosomal membrane permeability (38).

\section{Conclusion}

APOL1-RRV emerged in sub-Saharan Africa as a protection against sleeping disease caused by Trypanosoma brucei rhodesiense but increased the risk of CKD. This review provides a summary of existing evidence on APOL1 risk variants, as one of the players that cause kidney disease. Variety of environmental and interactive genetic variations influence the risk of developing nephropathy. Screening in the patients carrying APOL1 risk variants may lead to new preventive and therapeutic measures. Alternatively, targeting other mutable genes may direct toward preventive modalities to reduce the development of NDRD in various populations with two types of APOL1 risk variations. Therefore, further research on APOL1 could be an important step towards a better understanding of the problems of NDRD in these populations.

\section{Authors' contribution}

MAS contributed to the design and conception of the study. LVKSB prepared the draft of the manuscript. Critical revisions were done by AT and RT. All authors read and signed the final manuscript.

\section{Conflicts of interest}

The authors declare that they have no competing interests.

\section{Ethical considerations}

Ethical issues including plagiarism, double publication, and redundancy have been completely observed by the authors.

\section{Funding/Support}

None.

\section{References}

1. Saran R, Robinson B, Abbott KC, Agodoa LYC, Bhave N, Bragg-Gresham J, et al. US Renal Data System 2017 Annual Data Report: Epidemiology of Kidney Disease in the 
United States. Am J Kidney Dis. 2018;71:A7. doi: 10.1053/j. ajkd.2018.01.002.

2. Sepahi MA, Shajari A, Shakiba M, Shooshtary FK, Salimi MH. Acute glomerulonephritis: a 7 years follow up of children in center of Iran. Acta Med Iran. 2011;49:375-8.

3. Levin A, Stevens PE. Summary of KDIGO 2012 CKD Guideline: behind the scenes, need for guidance, and a framework for moving forward. Kidney Int. 2014;85:49-61. doi: $10.1038 /$ ki.2013.444.

4. Freedman BI, Parekh RS, Kao WHL. Genetic basis of nondiabetic end-stage renal disease. Seminars in nephrology. 2010;30:101-10. doi: 10.1016/j.semnephrol.2010.01.002.

5. Friedman DJ, Pollak MR. Apolipoprotein L1 and kidney disease in African Americans. Trends Endocrinol Metab. 2016;27:204-15. doi: 10.1016/j.tem. 2016.02.002.

6. Duchateau PN, Pullinger CR, Orellana RE, Kunitake ST, Naya-Vigne J, O'Connor PM, et al. Apolipoprotein L, a new human high density lipoprotein apolipoprotein expressed by the pancreas. Identification, cloning, characterization, and plasma distribution of apolipoprotein L. J Biol Chem. 1997;272:25576-82. doi: 10.1074/jbc.272.41.25576.

7. Kopp JB, Nelson GW, Sampath K, Johnson RC, Genovese G, An P, et al. APOL1 genetic variants in focal segmental glomerulosclerosis and HIV-associated nephropathy. J Am Soc Nephrol. 2011;22:2129-37. doi: 10.1681/ ASN.2011040388.

8. Tzur S, Rosset S, Shemer R, Yudkovsky G, Selig S, Tarekegn $\mathrm{A}$, et al. Missense mutations in the APOL1 gene are highly associated with end stage kidney disease risk previously attributed to the MYH9 gene. Hum Genet. 2010;128:34550. doi: 10.1007/s00439-010-0861-0.

9. Kao WH, Klag MJ, Meoni LA, Reich D, Berthier-Schaad Y, Li M, et al. MYH9 is associated with nondiabetic endstage renal disease in African Americans. Nat Genet. 2008;40:1185-92. doi: 10.1038/ng.232.

10. Kopp JB, Smith MW, Nelson GW, Johnson RC, Freedman BI, Bowden DW, et al. MYH9 is a major-effect risk gene for focal segmental glomerulosclerosis. Nat Genet. 2008;40:1175-84. doi: 10.1038/ng.226.

11. Vanhollebeke B, Pays E. The function of apolipoproteins L. Cell Mol Life Sci. 2006;63:1937-44. doi: 10.1007/s00018006-6091-x.

12. Limou S, Dummer PD, Nelson GW, Kopp JB, Winkler CA. APOL1 toxin, innate immunity, and kidney injury. Kidney international. 2015;88:28-34. doi: 10.1038/ki.2015.109.

13. Genovese G, Friedman DJ, Ross MD, Lecordier L, Uzureau P, Freedman BI, et al. Association of trypanolytic ApoL1 variants with kidney disease in African Americans. Science. 2010;329:841-5. doi: 10.1126/science.1193032.

14. Thomson R, Genovese G, Canon C, Kovacsics D, Higgins $\mathrm{MK}$, Carrington $\mathrm{M}$, et al. Evolution of the primate trypanolytic factor APOL1. Proc Natl Acad Sci USA. 2014;111:E2130-9. doi: 10.1073/pnas.1400699111.

15. Hu CA, Klopfer EI, Ray PE. Human apolipoprotein L1 (ApoL1) in cancer and chronic kidney disease. FEBS Lett. 2012;586:947-55. doi: 10.1016/j.febslet.2012.03.002.

16. Limou S, Nelson GW, Kopp JB, Winkler CA. APOL1 kidney risk alleles: population genetics and disease associations. Adv Chronic Kidney Dis. 2014;21:426-33. doi: 10.1053/j. ackd.2014.06.005.
17. Kopp JB, Nelson GW, Sampath K, Johnson RC, Genovese G, An P, et al. APOL1 genetic variants in focal segmental glomerulosclerosis and HIV-associated nephropathy. J Am Soc Nephrol. 2011;22:2129-37. doi: 10.1681/ asn.2011040388.

18. Freedman BI, Skorecki K. Gene-gene and gene-environment interactions in apolipoprotein L1 gene-associated nephropathy. Clin J Am Soc Nephrol. 2014;9:2006-13. doi: $10.2215 /$ cjn.01330214.

19. Parsa A, Kao WH, Xie D, Astor BC, Li M, Hsu CY, et al. APOL1 risk variants, race, and progression of chronic kidney disease. N Engl J Med. 2013;369:2183-96. doi: 10.1056/NEJMoa1310345.

20. Lipkowitz MS, Freedman BI, Langefeld CD, Comeau ME, Bowden DW, Kao WH, et al. Apolipoprotein L1 gene variants associate with hypertension-attributed nephropathy and the rate of kidney function decline in African Americans. Kidney Int. 2013;83:114-20. doi: 10.1038/ki.2012.263.

21. Madhavan SM, O’Toole JF, Konieczkowski M, Ganesan S, Bruggeman LA, Sedor JR. APOL1 localization in normal kidney and nondiabetic kidney disease. J Am Soc Nephrol. 2011;22:2119-28. doi: 10.1681/asn.2011010069.

22. Jotwani V, Shlipak MG, Scherzer R, Parekh RS, Kao WH, Bennett $\mathrm{M}$, et al. APOL1 genotype and glomerular and tubular kidney injury in women with HIV. Am J Kidney Dis. 2015;65:889-98. doi: 10.1053/j.ajkd.2015.02.329.

23. Freedman BI, Limou S, Ma L, Kopp JB. APOL1-associated nephropathy: a key contributor to racial disparities in CKD. Am J Kidney Dis. 2018;72:S8-s16. doi: 10.1053/j. ajkd.2018.06.020.

24. Larsen CP, Beggs ML, Saeed M, Ambruzs JM, Cossey LN, Messias NC, et al. Histopathologic findings associated with APOL1 risk variants in chronic kidney disease. Mod Pathol. 2015;28:95-102. doi: 10.1038/modpathol.2014.92.

25. Lee BT, Kumar V, Williams TA, Abdi R, Bernhardy A, Dyer C, et al. The APOL1 genotype of African American kidney transplant recipients does not impact 5-year allograft survival. Am J Transplant. 2012;12:1924-8. doi: 10.1111/j.1600-6143.2012.04033.x.

26. Kruzel-Davila E, Wasser WG, Aviram S, Skorecki K. APOL1 nephropathy: from gene to mechanisms of kidney injury. Nephrol Dial Transplant. 2016;31:349-58. doi: 10.1093/ndt/ gfu391.

27. Foster MC, Coresh J, Fornage M, Astor BC, Grams M, Franceschini N, et al. APOL1 variants associate with increased risk of CKD among African Americans. J Am Soc Nephrol. 2013;24:1484-91. doi: 10.1681/asn.2013010113.

28. Kumar V, Singhal PC. APOL1 and Kidney Cell Function. Am J Physiol Renal Physiol. 2019. doi: 10.1152/ ajprenal.00233.2019.

29. Wan G, Zhaorigetu S, Liu Z, Kaini R, Jiang Z, Hu CA. Apolipoprotein L1, a novel Bcl-2 homology domain 3-only lipid-binding protein, induces autophagic cell death. J Biol Chem. 2008;283:21540-9. doi: 10.1074/jbc.M800214200.

30. Nichols B, Jog P, Lee JH, Blackler D, Wilmot M, D’Agati V, et al. Innate immunity pathways regulate the nephropathy gene Apolipoprotein L1. Kidney Int. 2015;87:332-42. doi: 10.1038/ki.2014.270.

31. Dummer PD, Limou S, Rosenberg AZ, Heymann J, Nelson G, Winkler CA, et al. APOL1 Kidney Disease Risk Variants: 
An Evolving Landscape. Semin Nephrol. 2015;35:222-36. doi: 10.1016/j.semnephrol.2015.04.008.

32. Limou S, Dummer PD, Nelson GW, Kopp JB, Winkler CA. APOL1 toxin, innate immunity, and kidney injury. Kidney Int. 2015;88:28-34. doi: 10.1038/ki.2015.109.

33. Olabisi OA, Zhang J-Y, VerPlank L, Zahler N, DiBartolo S, 3rd, Heneghan JF, et al. APOL1 kidney disease risk variants cause cytotoxicity by depleting cellular potassium and inducing stress-activated protein kinases. Proc Natl Acad Sci U S A. 2016;113:830-7. doi: 10.1073/pnas.1522913113.

34. Cabezas S, Ho S, Ros U, Lanio ME, Alvarez C, van der Goot FG. Damage of eukaryotic cells by the pore-forming toxin sticholysin II: Consequences of the potassium efflux. Biochim Biophys Acta Biomembr. 2017;1859:982-92. doi: 10.1016/j.bbamem.2017.02.001.

35. Quaggin SE, George AL, Jr. Apolipoprotein 11 and the genetic basis for racial disparity in chronic kidney disease. J Am Soc Nephrol. 2011;22:1955-8. doi: 10.1681/ asn.2011090932.

36. Mishra A, Ayasolla K, Kumar V, Lan X, Vashistha H, Aslam $\mathrm{R}$, et al. Modulation of apolipoprotein L1-microRNA-193a axis prevents podocyte dedifferentiation in high-glucose milieu. Am J Physiol Renal Physiol. 2018;314:F832-F43. doi: 10.1152/ajprenal.00541.2017.

37. Beckerman P, Bi-Karchin J, Park AS, Qiu C, Dummer PD, Soomro I, et al. Transgenic expression of human APOL1 risk variants in podocytes induces kidney disease in mice. Nat Med. 2017;23:429-38. doi: 10.1038/nm.4287.

38. Lan X, Jhaveri A, Cheng K, Wen H, Saleem MA, Mathieson PW, et al. APOL1 risk variants enhance podocyte necrosis through compromising lysosomal membrane permeability. Am J Physiol Renal Physiol. 2014;307:F326-36. doi: 10.1152/ajprenal.00647.2013.

Copyright ( 2019 The Author(s); Published by Nickan Research Institute. This is an open-access article distributed under the terms of the Creative Commons Attribution License (http://creativecommons.org/licenses/by/4.0), which permits unrestricted use, distribution, and reproduction in any medium, provided the original work is properly cited. 